\title{
Hubungan physical activity dengan fine motor skills pada anak usia 4 tahun
}

\author{
Nur Indri Rahayu, Aini Dewi Monica*, Jajat, Kuston Sultoni \\ ${ }^{1}$ Program Studi Ilmu Keolahragaan, Program Sarjana, Universitas Pendidikan Indonesia. \\ Jalan Dr. Setiabudi No.229, Isola, Kec. Sukasari, Kota Bandung, Indonesia. \\ * Coressponding Author. E-mail: ainidewimonica@student.upi.edu
}

Received: August 30, 2020; Revised: September 13, 2020; Accepted: September 22, 2020

\begin{abstract}
Abstrak: Tujuan penelitian ini adalah menguji hubungan antara physical activity dengan fine motor skills pada anak usia 4 tahun. Metode yang digunakan adalah metode penelitian kuantitatif dengan pendekatan korelasional. Populasi dalam penelitian ini yaitu anak usia 4 tahun yang sedang menempuh pendidikan anak usia dini di PAUD, TK, dan KB di Kota Bandung. Jumlah sampel sebanyak 53 anak dengan teknik pengambilan sampel menggunakan purposive sampling. Instrumen yang digunakan berupa Accelerometer Actigraph dan 9-Hole Peg Test. Accelerometer Actigraph digunakan untuk mengukur tingkat physical activity atau aktivitas fisik dengan hasil yang menunjukan bahwa anak - anak paling banyak menghabiskan waktu di skor light daripada sedentary, moderate-to-vigorous dan vigorous. 9-Hole Peg Test digunakan untuk mengukur tingkat kemampuan motorik halus atau fine motor skills anak dengan hasil menunjukan bahwa anak lebih terampil dalam menggunakan tangan yang dominan. Data kemudian dianalisis dengan menggunakan Spearman Correlation Test. Hasil analisis data menunjukan tidak terdapat korelasi antara physical activity dengan fine motor skills baik pada tangan dominan $(\mathrm{p}=0,678>0,05)$ maupun dengan tangan non dominan $(\mathrm{p}=0,167>0,05)$ yang berarti tidak terdapat hubungan yang signifikan antara physical activity dengan fine motor skills pada anak usia 4 tahun.
\end{abstract}

Kata Kunci: Anak Usia 4 Tahun, Fine Motor Skills, Physical Activity

\section{The relationship between physical activity and fine motor skills in 4-year-old children}

\begin{abstract}
The purpose of this study was to examine the relationship between physical activity and fine motor skills in 4-year-old children. The method used is a quantitative research method with the correlation research approach. The population in this study were 4-year-old children who were taking early education in PAUD, TK, and KB in Bandung City. A total of 53 4-year-old children participated in this study by using a purposive sampling technique. The instrumen used were Accelerometer Actograph and 9-Hole Peg Test. The accelerometer actigraph is used to measure the level of physical activity and the results show that children spend the most time on the light score rather than sedentary, moderate-to-vigorous and vigorous score. 9-Hole Peg Test is used to measure the level of fine motor skills of children and the results showing that children are more skilled in using the dominant hand. Data were analyzed using the Spearman Correlation Test. The results of data analysis showed there is no correlation between physical activity and fine motor skills both in dominant hand $(p=0.678>0,05)$ and with the non-dominant hand $(p=0,167>0,05)$ which meant there are no significant relationship between physical activity and fine motor skills in 4-yearold children.
\end{abstract}

Keywords: 4-Year-Old Children, Fine Motor Skills, Physical Activity.

How to Cite: Rahayu, N. I., Monica, A. D., Jajat, J., \& Sultoni, K. (2021). Hubungan physical activity dengan fine motor skills pada anak usia 4 tahun. Jurnal Keolahragaan, 9(1), 118-127. DOI: https://doi.org/10.21831/jk.v9i1.34156

\section{PENDAHULUAN}

Physical activity (PA) merupakan aspek pendukung peningkatan kualitas hidup yang sangat penting bagi semua kalangan usia (Tremblay et al., 2011). Kurangnya physical activity dapat menjadi faktor peyebab penyakit kronis yang berakibat kematian (World Health Organization, 2018). Bahkan telah dibuktikan bahwa kurangnya physical activity berdampak pada penyakit jantung, diabetes dan 
kanker (Zahrt \& Crum, 2020). Namun sayangnya, banyak yang masih kurang sadar akan pentingnya physical activity. Sebagian besar anak usia dini memiliki tingkat physical activity yang rendah (Carson et al., 2017), padahal aktivitas fisik pada usia anak-anak dan remaja sangat penting karena jika tingkat aktivitas fisik rendah, maka akan berakibat terhadap status fisiologis yang kurang baik (Pate et al., 2010).

Aktivitas fisik sangat penting untuk perkembangan awal setiap anak dan mempengaruhi banyak aspek kesehatan anak (King, 2003). Organisasi Kesehatan pada masa ini merekomendasikan untuk menlakukan aktivitas fisik pada intensitas yang tinggi pada anak usia sekolah, hal ini dikaitkan dengan manfaat kesehatan jangka pendek dan jangka panjang yang sangat penting dalam domain fisik, emosional, sosial, dan kognitif di seluruh rentang hidup (WHO, 2017). Dengan demikian, sangat penting untuk mengintegrasikan aktivitas fisik ke dalam kehidupan anak-anak dan menetapkan pondasi dalam memfasilitasi dan mempertahankan gaya hidup aktif yang sehat sepanjang masa.

Meningkatkan aktivitas fisik pada anak-anak terutama anak usia dini secara otomatis akan mengurangi kebiasaan kurang gerak yang pada akhirnya dapat meningkatkan kualitas kesehatan dan kesejahteraan anak tersebut. Hal tersebut terjadi karena aktivitas fisik secara positif berhubungan dengan berbagai hasil psikologis, kognitif dan kardiometabolik anak, hal ini sangat penting untuk mengembangkan kebiasaan gaya hidup sehat sejak dini (Pozo-cruz et al., 2019). Meskipun alasan rendahnya tingkat aktivitas fisik belum dipahami dengan baik, namun Robinson \& Goodway (2013) dalam penelitiannya mengatakan bahwa keterampilan motorik dan aktivitas fisik dapat berkontribusi terhadap kesehatan anak usia dini. Dalam penelitian sebelumnya Robinson juga mengatakan bahwa keterlambatan dalam pengembangan keterampilan motorik telah dikaitkan dengan kemampuan fisik yang lebih rendah (Robinson, 2011). Anak usia dini adalah periode paling kritis dan cepat dari perkembangan motorik dan kognitif dalam kehidupan manusia (UNICEF, 2017); peningkatan aktivitas fisik dapat memberikan manfaat motorik dan kognitif di masa kanak-kanak dan remaja (Riethmuller, 2017). Oleh karena itu, memperoleh pemahaman yang lebih baik tentang potensi aktivitas fisik dalam meningkatkan keterampilan motorik dan kognisi pada anak-anak sangat penting.

Bukti ilmiah dan hasil penelitian menunjukkan bahwa aktivitas fisik memberikan manfaat kesehatan mendasar bagi anak kelompok usia 5-17 tahun. Tingkat aktivitas fisik yang tepat berkontribusi pada pengembangan jaringan tulang, otot, dan persendian yang sehat, sistem kardiovaskular yang sehat (jantung dan paru-paru), kesadaran neuromuskuler (koordinasi dan kontrol gerakan), dan juga memfasilitasi pemeliharaan berat badan yang sehat dan ideal. Selain itu, aktivitas fisik telah dikaitkan dengan manfaat psikologis pada anak usia dini yang bisa meningkatkan kontrol mereka atas gejala kecemasan dan depresi, membantu dalam pengembangan sosial dengan memberikan peluang untuk ekspresi diri, membangun kepercayaan diri, interaksi sosial dan integrasi (WHO, 2011). Perkembangan motorik halus anak di Indonesia tergolong rendah jika dibandingkan dengan negara-negara barat (Taju, Ismanto, \& Babakal, 2015). Berdasarkan data yang didapat pada studi yang dilakukan di Pendidikan Anak Usia Dini, ditemukan bahwa sebagian besar anak masih belum mampu dengan sempurna melakukan tugas motorik halus sesuai dengan usianya. Pada tahapan usia 36-48 bulan terdapat anak yang belum mampu menyusun 8 buah balok. Pada tahapan usia 48-60 bulan terdapat anak yang belum mampu menggambar bentuk lingkaran dan tanda silang dengan sempurna. Pada tahapan usia 60-72 bulan terdapat anak yang belum mampu menangkap bola kecil dengan kedua tangan. Ketrampilan motorik halus juga sangat penting bagi kemandirian anak (Luh, Yestiari, Raga, \& Ujianti, 2014). 10\% anak usia dini mengalami kesulitan dengan tugas motorik halus pada usia 4 tahun (Mchale \& Cermak, 1992). Padahal dalam kehidupan sehari-hari, kegiatan sekolah dan bermain membutuhkan ketangkasan motorik halus (Poole et al., 2005). Jika perkembangan motorik halus anak berjalan dengan baik maka anak akan dengan mudah melakukan hal-hal seperti mengikat tali sepatu, menyisir rambut, bahkan memegang alat tulis.

Perkembangan motorik halus tidak hanya dari gerak menulis saja, tetapi banyak kegiatan yang dapat mendukung perkembangan keterampilan motorik halus, seperti; mendeskripsikan konsep keterampilan yang mendasari, memberikan panduan dan penjelasan tentang keterampilan, menyajikan secara eksplisit fase keterampilan, memfokuskan perhatian anak pada keterampilan, memberikan arahan, memberikan peluang untuk melakukan praktek, memacu motivasi anak untuk terlibat aktif dalam kegiatan perkembangan yang dilakukan (Lim WY \& Koh M, 2006; Mohnsen B, 2008). Cara pengembangan motorik halus yang dilakukan oleh guru sebenarnya mengacu pada temuan penelitian 
seperti yang dijelaskan yaitu memberikan bimbingan dan memberikan kesempatan praktek seluasluasnya, memberikan arahan dan bimbingan yang sesuai dan memberikan motivasi agar anak selalu terlibat aktif dalam proses perkembangannya. Cara pembinaan yang dilakukan guru merupakan wujud empati guru terhadap anak dalam proses pendidikan. Memang cara ini dapat meningkatkan motivasi anak dalam proses perkembangan keterampilan motorik halusnya. Kajian tentang motivasi anak juga telah disinggung sebelumnya oleh peneliti lainnya, bahwa guru perlu memberikan motivasi dalam meningkatkan kompetensi dan keterampilannya (Patall EA Cooper H \& Robinson JC, 2008), kemudian motivasi dilakukan secara berulang-ulang dan terus menerus (Brown RM \& Robertson EM, 2007).

Hal ini untuk meningkatkan potensi anak secara bertahap (Censor N Sagi D \& Cohen LG, 2012). Syafrimen (2017) menyatakan bahwa pengembangan potensi anak dapat dilakukan dengan memberikan dukungan dan dorongan, membuka kesempatan, dan memberikan kesadaran. Sejalan dengan hasil penelitian ini yang menemukan bahwa dalam mengembangkan keterampilan motorik halus anak, guru perlu memberikan arahan dan memberikan kesempatan kepada anak untuk melakukan kegiatan praktik yang dilakukan selama sekolah. Selain itu, guru perlu meningkatkan keterampilan motorik halus anak secara bertahap, dan mengevaluasi perkembangan keterampilan motorik halus anak yang telah dicapai (Atasoy, 2006; Dorfberger S Adi-Japha E \& Karni A, 2007, 2014). Dalam proses pengembangannya guru juga dituntut untuk menyadari betul akan perbedaan keterampilan motorik halus setiap anak (Leah E, 2012). Beberapa ahli menemukan bahwa anak lakilaki cenderung lebih maju daripada anak perempuan (Barnett L M van Beurden et al, 2009; Walter C, 2011). Peneliti setuju dengan beberapa penelitian, karena salah satu langkah untuk perkembangan motorik halus anak adalah dengan cara guru mengamati anak secara individu maupun kelompok, dan secara konstan mengevaluasi perkembangan motorik halus anak secara berkesinambungan.

Beberapa ilmuwan menyimpulkan adanya hubungan antara status keterampilan motorik anakanak dengan aktivitas fisik meraka (Ulrich, 2013). Teori belajar motorik yang dikemukakan oleh Croce menekankan bahwa keterampilan motorik diperoleh dengan menggunakan strategi spesifik dan disempurnakan melalui banyak pengulangan dan transfer keterampilan ke tugas-tugas lain, hal tersebut dapat dikaitkan dengan penelitian ini, dimana aktivitas fisik yang dilakukan secara bertahap dan berulang-ulang akan mempengaruhi kemampuan motorik anak (Prisyana \& Nurhayati, 2019). Berbagai sumber yang mengatakan bahwa terdapat hubungan yang signifikan antara skor keterampilan motorik anak dengan level aktivitas fisik berfokus pada kedua kalsifikasi keterampilan motorik yaitu fine motor skills dan gross motor skills.Sehingga berdasarkan uraian tersebut diatas, peneliti tertarik untuk melakukan penelitian untuk mempelajari hubungan antara physical activity dengan fine motor skills pada anak usia dini.

\section{METODE}

Penelitian ini merupakan jenis penelitian non-eksperimen dengan metode kuantitatif dan menggunakan desain penelitian korelasi. Partisipan yang terlibat dalam penelitian ini adalah tim penelitian yang berjumlah 11 orang, 5 dosen pembimbing, dan sampel yang merupakan anak-anak usia 4 tahun yang berada di PAUD (Pendidikan Anak Usia Dini), TK (Taman Kanak-kanak) dan Kober (Kelompok Bermain) di wilayah Kota Bandung sebanyak 53 orang beserta orangtua atau wali mereka. Selain itu partisipan dalam penelitian ini adalah para guru dan kepala sekolah yang ikut serta dalam membantu mensosialisasikan penelitian ini kepada orang tua siswa.

Populasi yang dilibatkan dalam penelitian ini yaitu anak-anak PAUD, TK dan Kober di Wilayah Kota Bandung. Pengambilan sampel dengan menggunakan teknik purposive sampling yaitu 53 anak dengan kriteria berusia 4 tahun. Setelah menentukan masalah dan populasi, hal pertama yang dilakukan peneliti bersama tim adalah melakukan survey ke PAUD, TK dan Kober di Wilayah Kota Bandung untuk mencari anak dengan kriteria yang akan dijadikan sampel yaitu yang berusia 4 tahun. Selanjutnya peneliti melakukan sosialisasi dengan pihak sekolah dan orang tua/wali siswa mengenai penelitian ini secara rinci. Kemudian orang tua diberikan concern form yang menyatakan setuju anaknya berpartisipasi dalam penelitian ini.

Instrumen yang digunakan dalam penelitian ini yaitu Accelerometer Atigraph dan 9-Hole Peg Test. Accelerometer Actigraph adalah monitor kecil dan ringan yang dikenakan dengan bantuan sabuk elastis di sekitar pinggang untuk mengukur intensitas Physical Activity yang terkait dengan pergerakan 
Jurnal Keolahragaan 9 (1), 2021 - 121

Nur Indri Rahayu, Aini Dewi Monica, Jajat, Kuston Sultoni

anak (Choi, Chen, Acra, \& Buchowski, 2009). Actigraph memiliki validitas yang dapat diterima untuk pengukuran aktivitas selama berkegiatan pada anak-anak pra-sekolah (Gwyneth Davies, John J Reilly, Amy J McGowan \& Malcolm H Granat, 2013). Dalam penelitian ini, actigraph diprogram untuk merekam aktivitas fisik anak dan setelah itu kemudian data diunduh dengan menggunakan perangkat lunak khusus.Alat ini dapat dilepaskan kembali pada 5 hari setelah pemasangan untuk kemudian didapatkan hasil rekaman aktivitas fisik sampel(Ruiz, Gesell, Buchowski, Lambert, \& Barkin, 2011). Sedangkan 9-Hole Peg Test merupakan suatu timed test dimana sembilan pasak dimasukkan dan dikeluarkan kembali dari sembilan lubang dengan test waktu dari masing-masing tangan (Poole et al., 2005). Prosedur yang dilakukan dengan instrumen ini yaitu, 9-Hole Peg Test diletakkan di depan subjek dengan sisi wadah yang sama dengan tangan yang diuji. Tangan yang dominan diujiterlebih dahulu. Subjek menyelesaikan satu uji coba praktik diikuti oleh tes waktu yang sebenar-benarnya untuk masing-masing tangan. Untuk tangan yang tidak dominan, pegboard diputar sehingga wadah berada di sisi yang sama dengan tangan yang tidak dominan (Mathiowetz, 2015). Selanjutnya yaitu melakukan pengolahan data atau tahap analisis untuk mendapatkan kesimpulan dari hasil penelitian. Analisis data menggunakan Spearman Correlation untuk mengetahui apakah terdapat hubungan antara physical activity dengan fine motor skills pada anak usia dini.

\section{HASIL DAN PEMBAHASAN}

\section{Hasil}

Berdasarkan hasil penelitian yang disajikan pada gambar 1. menunjukkan bahwa pada data physical activity sampel yang memiliki tingkat sedentary sebanyak 13\%, sampel yang memiliki tingkat light sebanyak 56\%, sampel yang memiliki tingkat moderate sebanyak 20\%, dan sampel yang memiliki tingkat vigorous sebanyak $11 \%$. Berarti jika dilihat dari deskriptif data tersebut, tingkat physical activity yang mendominasi yaitu tingkat light daripada moderate dan vigorous.

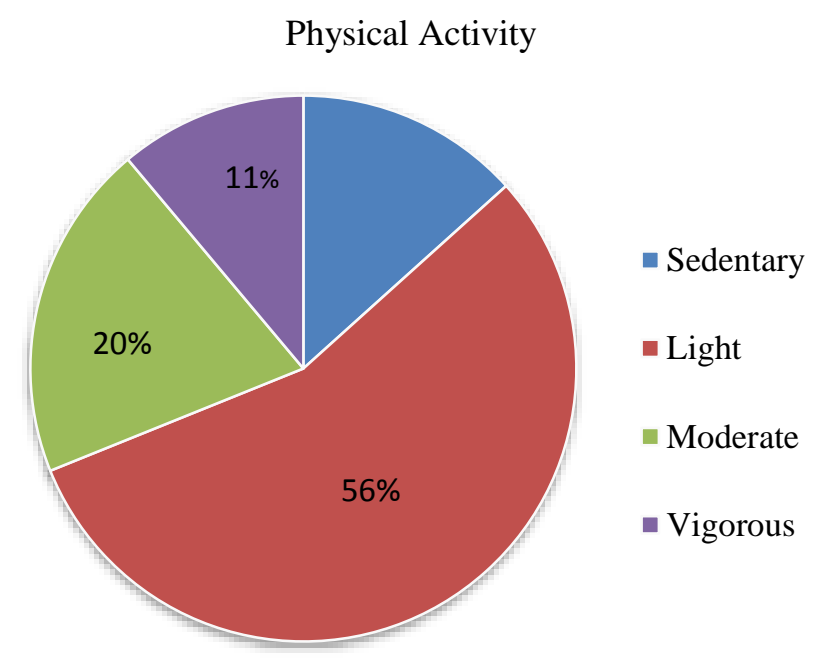

Gambar 1. Data Hasil Penelitian Berdasarkan Tingkat Physical Activity

Gambar 2. merupakan data deskriptif tingkat fine motor skills dari hasil pengukuran yang dilakukan. Hasil menunjukkan bahwa sampel yang memiliki tingkat fine motor skills tinggi sebanyak $23 \%$, sampel yang memiliki tingkat fine motor skills sedang sebanyak $60 \%$ dan sampel yang memiliki tingkat fine motor skills rendah sebanyak 17\%. Berdasarkan dari hasil deskriptif data tersebut, maka hasil pengukuran fine motor skills pada sampel didominasi oleh tingkat fine motor skills sedang. 
Jurnal Keolahragaan 9 (1), 2021 - 122

Nur Indri Rahayu, Aini Dewi Monica, Jajat, Kuston Sultoni

Fine Motor Skills

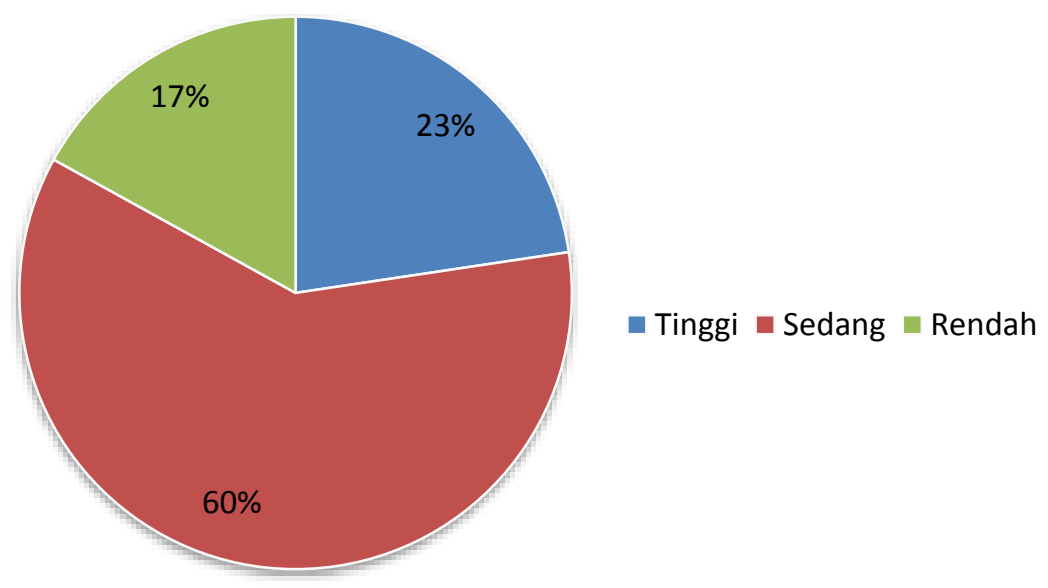

Gambar 2. Data Hasil Penelitian Berdasarkan Tingkat Fine Motor Skills

Dari Tabel 1. dapat diketahui bahwa nilai Sig. 0,717 > 0,05 yang berarti tidak ada hubungan yang signifikan.

Tabel 1. Korelasi antara physical activity dengan fine motor skills

\begin{tabular}{lll}
\hline & Sig. & Keterangan \\
\hline $\begin{array}{l}\text { Korelasi physical } \\
\text { activity dengan fine } \\
\text { motor skills }\end{array}$ & 0,717 & Tidak Ada \\
\hline
\end{tabular}

Berdasarkan hasil dari uji spearman correlation pada tabel diatas menunjukan nilai sig. 0,717 $>0,05$ yang dapat diartikan bahwa tidak terdapat hubungan yang signifikan antara physical activity dengan fine motor skills pada anak usia 4 tahun.

Tujuan dari penelitian ini adalah untuk mengevaluasi secara komprehensif mengenai hubungan aktivitas fisik pada keterampilan motorik dalam hal ini fine motor skills. Oleh karena itu, diperlukan lebih banyak penelitian dengan ukuran sampel yang lebih besar. Anak usia dini dianggap sebagai periode waktu kritis untuk membangun perilaku sehat seperti aktivitas fisik (Puder, 2011). Program aktivitas fisik menyediakan lingkungan untuk perkembangan keterampilan motorik anakanak, dengan keterampilan motorik menjadi dasar untuk aktivitas fisik selama tahun-tahun awal dan tahun-tahun berikutnya (Jones et al, 2011). Secara keseluruhan, bukti mengenai efektivitas intervensi aktivitas fisik pada pengembangan keterampilan motorik kuat. Meskipun demikian, mengidentifikasi dosis intervensi aktivitas fisik yang bertujuan untuk meningkatkan keterampilan motorik anak prasekolah harus menjadi fokus penelitian selanjutnya (Zeng et al., 2017)

Fine motor skills merupakan bagian dari keterampilan gerak dasar, yaitu gerakan dasar bagi anak yang harus dikuasai sejak kecil. Keterampilan ini harus diajarkan dengan baik, sehingga mengetahui tingkat dasar anak dalam keterampilannya merupakan landasan penting untuk merancang program pengembangan motorik yang tepat bagi anak dan mengusulkan kebijakan nasional yang tidak hanya berharga bagi anak, tetapi juga bagi masyarakat dan bangsa. Untuk itu, sebaiknya dilakukan asesmen keterampilan motorik anak di Indonesia dalam skala yang lebih besar, agar Indonesia dapat bersaing dengan negara lain dalam mengembangkan anak menjadi lebih sehat dan mampu menghadapi tantangan global (Bakhtiar, 2017).

Perkembangan keterampilan motorik dasar (FMS) merupakan aspek penting dari anak usia dini. FMS adalah pola pergerakan kasar dan halus; Pola gerakan kasar melibatkan kelompok otot besar dan pola gerakan halus melibatkan aktivasi kelompok otot yang lebih kecil. Keterampilan motorik umumnya dipisahkan menjadi lokomotor, objek kontrol, dan keterampilan stabilitas. Keterampilan lokomotor melibatkan navigasi tubuh melalui ruang dengan pola gerakan khusus (misalnya, simetris, 
asimetris, lateral); Keterampilan objek kontrol melibatkan manipulasi item baik dengan memproyeksikan atau menerimanya; dan keterampilan stabilitas melibatkan stabilisasi pusat gravitasi tubuh (Clark, 2002).

Fine motor skills merupakan salah satu komponen penting dalam aktivitas anak di sekolah. Sekitar 30-60\% dalam sehari, guru perlu memberikan tugas motorik kepada anak-anak di sekolah, di mana pemahaman keterampilan motorik dapat membantu meningkatkan kemampuan siswa di bidang akademik (Chin-Kai Lin, 2014). Pada usia 3 tahun anak sudah memiliki kemampuan memegang benda dengan ibu jari dan telunjuk, pada usia 4 tahun motorik halus pada anak sudah mulai berkembang, seperti membangun menara tinggi dengan mainan batu bata, pada usia 5 tahun motorik halus pada anak sudah mulai berkembang. Keterampilan motorik anak akan berkembang ke tingkat yang lebih tinggi, jari, lengan, dan tangan semuanya bergerak di bawah koordinasi mata-tangan, dan anak usia 6 tahun dapat mengikat tali sepatu, dan berdandan (James K. H \& Engelhardt L, 2012). Pengembangan fine motor skills berkaitan dengan manipulasi objek manual, seperti menulis, menenun tali, menyusun balok, mengikat tali sepatu, membalik halaman buku, memotong dengan gunting, memainkan adonan, dan membuat bentuk dari kertas lipat (Houwen, 2009). Selain itu, fine motor skills dapat berupa kegiatan seperti memotong dengan gunting, mewarnai, menggambar dengan pensil dan krayon (Punum Bhatia Alan Davis \& Ellen Shamas-Brandt et al, 2015). Oleh karena itu, guru perlu memahami perkembangan motorik halus anak selama di sekolah.

Fine motor skills adalah kemampuan untuk mengontrol gerakan melalui aktivitas terkoordinasi dari sistem saraf dan otot seperti gerakan jari dan tangan (McPhillips \& Jordan-Black, 2007). Menurut McPhillips dan Jordan-Black (2007) Fine motor skills di taman kanak-kanak harus sesuai dengan kurikulum yang diukur melalui tugas-tugas perkembangan dengan indikator pencapaian, dan sesuai dengan standar pendidikan anak usia dini. Indikator perkembangan fine motor skills anak dapat dirancang selama satu tahun (L. S.Pagani, Fitzpatrick, C., Archambault, I., \& Janosz, M., 2010). Beberapa penelitian menyoroti peran fine motor skills dalam perkembangan kognitif dan matematika (Luo, 2007; LS Pagani, Fitzpatrick, C ., Archambault, I., \& Janosz, M, 2010), peran fine motor skills juga dikaji dalam kaitannya dengan membaca dan perkembangan literasi (D. Grissmer et all 2010).

Contoh cara mengembangkan fine motor skills anak adalah dengan memegang dan meletakkan manik-manik pada batang (Piek, 2008; Rigoli, 2012), memotong dan menulis dengan cepat dan jelas (Tseng, 2010; Wilson, 2009). Hal ini dapat dilakukan oleh anak, karena pada masa-masa awal anak mengalami masa tumbuh kembang yang pesat (Suzanne Houwen, 2016). Perkembangan fine motor skills pada anak usia dini memungkinkan mereka untuk mengeksplorasi, bermain, dan memanipulasi objek atau alat dalam aktivitas sehari-hari (Henderson, 2006).

Aktivitas fisik yang rendah terhadap keterampilan motorik dapat berdampak pada perkembangan keterampilan motorik anak (Hurter Z \& Pienaar E, 2007; Malina R M, 2012). Guru perlu melakukan berbagai pendekatan agar anak dapat aktif dan percaya diri dalam bergerak, serta memiliki partisipasi yang lebih tinggi dalam proses pengembangan fine motor skills (Robinson LE Reynolds J Wadsworth \& Logan, 2010). Beberapa penelitian menemukan bahwa aktivitas fisik sangat penting dalam mengembangkan keterampilan motorik anak (Gallahue D L \& Ozmun J C, 2006; Harvey W J \& Mcgill U, 2007), justru anak harus aktif secara fisik untuk mengembangkan keterampilan motorik baru melalui gerakan motorik (Pienaar, 2016). Fine motor skills sangat penting dalam perkembangan awal anak (D. W. Grissmer, Grimm, K. J., Aiyer, S. M., Murrah, W. M., \& Steele, J. S., 2010). Sehingga guru perlu memberikan kesempatan kepada anak untuk berlatih secara spontan dengan berbagai materi, karena keberhasilan anak di sekolah terkait dengan koordinasi beberapa keterampilan (Pianta, 2007).

Hasil penelitian ini bertolak belakang dengan penelitian yang dilakukan oleh Wrotniak et al., (2006) yang berjudul The Relationship Between Motor Profiency and Physical Activity in Children. Dimana hasil dari penelitian yang dilakukan oleh Wrotniak et al. yaitu, keterampilan motorik anakanak secara positif berhubungan dengan jumlah aktivitas dan presentase waktu dalam intensitas aktifitas fisik sedang hingga kuat dan berbanding terbalik dengan presentasi waktu dalam aktifitas menetap. Penelitian lain yaitu penelitian yang berjudul Motor Skill Performance and Physical Activity in Preschool Children yang dilakukan oleh Williams et al., (2008). Dengan hasil penelitian menyatakan bahwa anak-anak dengan kinerja keterampilan motorik yang lebih buruk kurang aktif daripada anak-anak dengan keterampilan motorik yang lebih baik. Hubungan antara kinerja 
keterampilan motorik dan aktifitas fisik ini dapat menjadi penting bagi kesehatan anak-anak, terutama pencegahan obesitas di Indonesia. Penelitian ini mendorong orang tua untuk memantau keterampilan motorik dan untuk menekankan anak - anak terlibat dalam kegiatan yang meningkatkan knerja keterampilan motorik. Beberapa penelitian yang bertolak belakang dengan hasil dari penelitian ini dapat dikarenakan penelitian yang telah dilakukan oleh Wrotniak et al., dan Williams et al., menggunakan skor atau nilai keterampilan yang terdiri dari motorik halus dan motorik kasar. Sedangkan dalam penelitian ini menggunakan skor fine motor skills.

Penelitian ini didukung oleh penelitian yang telah dilakukan oleh Prisyana \& Nurhayati (2019) yang berjudul Hubungan Antara Status Gizi Dan Aktivitas Fisik Dengan Kemampuan Motorik Pada Siswa Kelas Atas Di Sdn Betiting Gresik yang hasilnya menunjukkan bahwa tidak terdapat hubungan antara aktivitas fisik dengan kemampuan motorik anak. Mchale \& Cermak (1992) dalam penelitiannya yang berjudul Fine Motor Activities in Elementary School: Preliminary Findings and Provisional Implications for Children With Fine Motor Problems menyatakan bahwa anak dengan masalah pada fine motor skills dianjurkan untuk meningkatkan kemampuan motorik halus dengan cara yaitu guru dan tenaga pengajar membuat alternatif pembelajaran dengan memodifikasi latihan dan cara belajar motorik halus. Penelitian tersebut tidak menyebutkan bahwa kurangnya fine motor skills berhubungan atau dapat diatasi dengan aktivitas fisik. Kemudian juga terdapat penelitian yang dilakukan oleh Niechwiej-szwedo et al., (2017) yang berjudul Human Movement Science Association between fine motor skills and binocular visual function in children with reading difficulties, yang menyimpulkan bahwa fine motor skills atau fine motor skills memiliki hubungan dengan kemampuan membaca, dimana semakin kurang fine motor skills maka semakin kurang juga kemampuan membaca pada anak. Penelitian yang dilakukan oleh Suggate, Pufke, \& Stoeger, (2019) yang berjudul Early Childhood Research Quarterly Children' s fine motor skills in kindergarten predict reading in grade 1 juga menjelaskan bahwa fine motor skills atau fine motor skills memiliki hubungan dengan kemampuan membaca yang kemungkinan juga memiliki hubungan baik dengan kemampuan akademik lainnya seperti kemampuan matematika dan sebagainya.

\section{SIMPULAN}

Berdasarkan hasil analisis data dan pembahasan tentang hubungan antara physical activity dengan fine motor skills pada anak usia 4 tahun, dapat disimpulkan bahwa tidak terdapat hubungan yang signifikan antara physical activity dengan fine motor skills pada anak usia 4 tahun di wilayah Kota Bandung. Direkomendasikan untuk penelitian selanjutnya agar mengambil sampel yang lebih banyak dan jangkauan populasi yang lebih luas serta dengan metode penelitian eksperimen.

\section{DAFTAR PUSTAKA}

Atasoy, S. v. A., A.R. (2006). Yapılandırmacı ogrenme kuramına gore gelistirilen calısma yapraklarının uygulama surecinin degerlendirilmesi. Milli Egitim Dergisi, 170, 157- 175.

Bakhtiar, S. (2017). Fundamental Motor Skill among 6-Year-Old Children in Padang, West Sumatera , Indonesia, 10(5), 155-158. https://doi.org/10.5539/ass.v10n5p155

Barnett L M van Beurden et al. (2009). Childhood motor skill proficiency as a predictor of adolescent physical activity. Journal of Adolescent Health, 44, 252-259.

Brown R M \& Robertson E M. (2007). "Off-line processing: Reciprocal interactions between declarative and procedural memories. Journal of Neuroscience, 27, 10468-10475.

Carson, V., Lee, E., Hewitt, L., Jennings, C., Hunter, S., Kuzik, N., ... Tremblay, M. S. (2017). Systematic review of the relationships between physical activity and health indicators in the early years ( 0-4 years ), 17(Suppl 5). https://doi.org/10.1186/s12889-017-4860-0

Censor N Sagi D \& Cohen LG. (2012a). Commonmechanisms of human perceptual and motor learning. Nature Reviews Neuroscience, 13, 658-664.

Choi, L., Chen, K. Y., Acra, S. A., \& Buchowski, M. S. (2009). Distributed lag and spline modeling for predicting energy expenditure from accelerometry in youth. Journal of Applied Physiology, $108(2), 314-327$.

Chin-Kai Lin, L.-F. M., Ya-Wen Yu, Che-Kuo Chen, Kuan-Hua Li. (2014). Factor analysis of the 
Jurnal Keolahragaan 9 (1), 2021 - 125

Nur Indri Rahayu, Aini Dewi Monica, Jajat, Kuston Sultoni

Contextual Fine Motor Questionnaire in Children. Research in Developmental Disabilities, 35, 512-519.

Dorfberger S Adi-Japha E \& Karni A. (2007). Reduced susceptibility to interference in the consolidation of motor memory before adolescence. PLoS ONE, 2, e240.

Dorfberger S Adi-Japha E \& Karni A. (2014). Reduced susceptibility to interference in the consolidation of motor memory before adolescence. PLoS ONE, 2, e240.

Gallahue D L \& Ozmun J C. (2006). Understanding motor development. Infants, children, adolescents, adults (6th ed.). NY: McGraw-Hill.

Grissmer, D., Grimm, K. J., Aiyer, S. M., Murrah, W. M., \& Steele, J. S. (2010). Fine motor skills and early comprehension of the world: Two new school readiness indicators. Developmental Psychology, 46, 1008-1017.

Gwyneth Davies, John J Reilly, Amy J McGowan, P. M. D., \& Malcolm H Granat, and J. Y. P. (2013). Validity, Practical Utility, and Reliability of the Activpal in Preschool Children, 44(January), 761-768.

Harvey W J \& Mcgill U. (2007). Fundamental movement skills and associated physical activity experiences of children with ADHD. Humanities and Social Sciences, 68(3), 927- 932.

Henderson, A., \& Pehoski, C. (2006). Hand function in the child: Foundations for remediation. St. Louis, MO Mosby Elsevier.

Houwen, S., Visscher, C., Koen, A. P. M., \& Lemmink, E. H. (2009). Motor skill performance of children and adolescents with visual impairments: A review. Exceptional Children, 75, 464-492.

Hurter Z \& Pienaar E. (2007). Fisieke aktiwiteitsvlakke en patrone van dertien- totvyftienjarige seuns in die Noordwes- Provinsie: THUSA-BANA-studie. Suid- Afrikaanse Tydskrif vir Navorsing in Sport. Liggaamlike Opvoedkunde en Ontspanning, 29(2), 41-57.

James K. H \& Engelhardt L. (2012). The effects of handwriting experience on functional brain development in pre-literate children. Trends in Neuroscience and Education, 1, 32-42.

Jones R. A., Riethmuller A., Hesketh K., Trezise J., Batterham M., Okely A. D. Promoting fundamental movement skill development and physical activity in early childhood settings: A cluster randomized controlled trial. Pediatric exercise science. 2011;23(4):600-615. doi: 10.1123/pes.23.4.600.

Leah E, R. E., Kipling Webster S, Wood Logan W, Amarie Lucas Laura T, Barber. (2012). Teaching Practices that Promote Motor Skills in Early Childhood Settings. Early Childhood Educ, 40, 7986.

Lim W Y \& Koh M. (2006). E-learning: new opportunities for teaching and learning in gymnastics. British Journal of Teaching Physical Education, 37(1), 22-25.

Luh, N., Yestiari, A., Raga, G., \& Ujianti, P. R. (2014). PENERAPAN METODE PEMBERIAN TUGAS MELALUI KEGIATAN MENCOCOK BERBANTUAN MEDIA GAMBAR UNTUK MENINGKATKAN MOTORIK HALUS, 2(1).

Luo, Z., Jose, P. E., Huntsinger, C. S., \& Pigott, T. D. (2007). Fine motor skills and mathematics achievement in East Asian American and European American kindergartners and first graders. British Journal of Developmental Psychology, 25, 595-614.

Mathiowetz, V. (2015). Adult Nonns For The Nine Hole Peg Test OfFinger Dexterity.

Malina R M. (2012). Movement proficiency in childhood: implications for physical activity and youth sport. Kinesiologia Slovenica, 18(3), 19-34.

McPhillips, \& Jordan-Black. (2007). The effect of social disadvantage on motor development in young children: A comparative study. Journal of Child Psychology and Psychiatry, 48, 1214-1222.

Mchale, K., \& Cermak, S. A. (1992). Fine Motor Activities in Elementary School: Preliminary Findings and Provisional Implications for Children With Fine Motor Problems, 46(1983), 898903. 
Pate, R. R., Freedson, P. S., Sallis, J. F., Taylor, W. C., Sirard, J., Trost, S. G., ... Ph, D. R. (2010). Compliance with Physical Activity Guidelines : Prevalence in a Population of Children and Youth, 2797(01), 20-22.

Patall E A Cooper H \& Robinson J C. (2008). The effects of choice on intrinsic motivation and related outcomes: A metaanalysis of research findings. Psychological Bulletin, 134(2), 270-300.

Pagani, L. S., Fitzpatrick, C., Archambault, I., \& Janosz,M. . (2010). School readiness and later achievement: A French Canadian replication and extension. Developmental Psychology, 46, 984-994.

Piek J P Dawson L Smith L M \& Gasson N. (2008). The role of early fine and gross motor development on later motor and cognitive ability. Human Movement Science, 27, 668-681.

Pianta, R. C., Cox, M. J., \& Snow, K. L. (2007). School readiness and the transition to kindergarten in the era of accountability. Baltimore: Brookes.

Poole, J. L., Otr, L., Burtner, P. A., Otr, L., Torres, T. A., Mcmullen, C. K., ... Otr, L. (2005). Measuring Dexterity in Children Using the Nine-hole Peg Test, 348-351. https://doi.org/10.1197/j.jht.2005.04.003

Pozo-cruz, B., Perales, F., Parker, P., Lonsdale, C., Noetel, M., Hesketh, K. D., \& Sanders, T. (2019). Joint physical-activity / screen-time trajectories during early childhood: socio- demographic predictors and consequences on health-related quality-of-life and socio- emotional outcomes, $1-$ 13.

Puder J. J., Marques-Vidal P., Schindler C., et al. Effect of multidimensional lifestyle intervention on fitness and adiposity in predominantly migrant preschool children (Ballabeina): Cluster randomised controlled trial. BMJ. 2011;343(7830) doi: 10.1136/bmj.d6195.d6195

Punum Bhatia Alan Davis \& Ellen Shamas-Brandt et al. (2015). Educational Gymnastics: The Effectiveness of Montessori Practical Life Activities in Developing Fine Motor Skills in Kindergartners. Early Education and Development, 26:4, 594-607.

Prisyana, D. I., \& Nurhayati, F. (2019). HUBUNGAN ANTARA STATUS GIZI DAN AKTIVITAS FISIK DENGAN KEMAMPUAN MOTORIK PADA SISWA KELAS ATAS DI SDN BETITING GRESIK, 07, 315-320.

Riethmuller A. M., Jones R. A., Okely A. D. Efficacy of interventions to improve motor development in young children: A systematic review. Pediatrics. 2009;124(4):e782-e792. doi: 10.1542/peds.2009-0333.

Rigoli, D., Piek,J.P.,Kane,R.,\& Oosterlaan,J. (2012). An examination of there lationship between motor coordination and executive functionsin adolescents. Developmental Medicine \&Child Neurology, 54, 1025-1031.

Robinson, L. E. (2011). The relationship between perceived physical competence and fundamental motor skills in preschool children. Child: Care, Health and Development, 37(4), 589-596.

Robinson, L. E., \& Goodway, J. D. (2013). Instructional Climates in Preschool Children Who Are, (December 2014), 37-41. https://doi.org/10.1080/02701367.2009.10599591

Robinson L E Reynolds J Wadsworth \& Logan. (2010). The effects of physical play instructional climates on physical activity in preschool-age children [Abstract]. Science and Sports, 25, 4-13.

Ruiz, R., Gesell, S. B., Buchowski, M. S., Lambert, W., \& Barkin, S. L. (2011). The relationship between Hispanic parents and their preschool-aged children's physical activity. Pediatrics, 127(5), 888-895.

Suzanne Houwen, L., Annettevander Putten,Carla Vlaskamp. (2016). The interrelationships between motor,cognitive, and language developmentin children with and without intellectual and developmental disabilities. Research in Developmental Disabilities, 53-54(2016), 19-31.

Taju, C. M., Ismanto, A. Y., \& Babakal, A. (2015). HUBUNGAN STATUS PEKERJAAN IBU DENGAN PERKEMBANGAN MOTORIK HALUS DAN MOTORIK KASAR ANAK USIA PRASEKOLAH DI PAUD GMIM BUKIT HERMON DAN TK IDHATA KECAMATAN MALALAYANG KOTA MANADO, 3, 0-7. 
Tremblay, M. S., Warburton, D. E. R., Janssen, I., Paterson, D. H., Latimer, A. E., Rhodes, R. E., ... Duggan, M. (2011). New Canadian Physical Activity Guidelines. Appl. Physiol. Nutr. Metab, 36, 36-46. https://doi.org/10.1139/H11-009

Tseng, M. H., Fu, C. P., Wilson, B. N., \& Hu, F. C. (2010). Psychometric properties of a Chinese version of the Developmental Coordination Disorder Questionnaire in community-based children. Research in Developmental Disabilities, 31, 33-45.

Ulrich, B. D. (2013). Research Quarterly for Exercise and Sport Perceptions of Physical Competence, Motor Competence, and Participation in Organized Sport: Their Interrelationships in Young Children Perceptions of Physical Competence, Motor Competence, and Participation i, (March), $37-41$.

Walter C. (2011). In-school physical activity patterns of primary school learners from disadvantaged schools in South Africa. African Journal for Physical,." Health Education Recreation and Dance, 17(4:2), 779e 788 .

Wilson, B. N., Crawford, S. G., Green, D., Roberts, G., Aylott, A., \& Kaplan, B. J. (2009). Psychometric properties of the revised Developmental Coordination Disorder Questionnaire. Journal of Physical and Occupational Therapy in Pediatrics, 29(2), 182-202.

World Health Organization, W. (2018). Physical Activity.

Zahrt, O. H., \& Crum, A. J. (2020). E ff ects of physical activity recommendations on mindset, behavior and perceived health is. Preventive Medicine Reports, 17(November 2019), 101027. https://doi.org/10.1016/j.pmedr.2019.101027

Zeng, N., Ayyub, M., Sun, H., Wen, X., Xiang, P., \& Gao, Z. (2017). Effects of Physical Activity on Motor Skills and Cognitive Development in Early Childhood: A Systematic Review, 2017. 